\title{
ANALISIS STRATEGI BISNIS PT. XYZ UNTUK BERKEMBANG DALAM INDUSTRI SAAS
}

\author{
Christian Michael Budijanto \\ Program Studi Magister Manajemen Universitas Tarumanagara \\ christian_michae195@yahoo.com \\ Rina Adi Kristianti \\ Program Studi Magister Manajemen Universitas Tarumanagara
}

\begin{abstract}
This research aims to analyze the strategies that have been pursued by PT. XYZ for long term strategy improvement and see opportunities that can be used to develop in the SAAS (software as a service) industry. Analytical method used to support research with three phases, ie Input Level, Match Stage, and Decision Stage. These three stages can help identify, evaluate and select strategies in PT XYZ. In this study compare products from PT. XYZ is Sales1CRM with competitors in the SAAS industry that provides CRM services. Competitors selected by authors include: HashMicro CRM, EspoCRM, and Barantum CRM as one of SAAS-based CRM service providers in Indonesia. Based on the results of the research which has been done by using three phases, that is, in the first phase of PT XYZ able to exploit existing opportunities and minimize its external threat, PT XYZ has more strength than its weakness factor, but PT. XYZ is still under HashMicro because the number of services provided is limited. While in the second stage, the SWOT matrix provides a SO strategy recommendation and in the SPACE matrix provides recommendations for aggressive strategy to continue to expand its market share, and the Internal-External Matrix recommends growth and build strategy. In the third stage, QSPM provides three alternative recommendations, namely, product development strategy in order to continue to grow following technology development and second alternative is market penetration strategy and horizontal integration.
\end{abstract}

\begin{abstract}
Abstrak : Penelitian ini bertujuan untuk menganalisis strategi yang sudah dijalani PT XYZ untuk perbaikan strategi jangka panjang dan melihat peluang yang dapat digunakan untuk berkembang dalam industri SAAS (software as a service). Metode analisis yang digunakan untuk mendukung penelitian dengan tiga tahap, yaitu Tahap Input, Tahap Pencocokan, dan Tahap Keputusan. Ketiga tahap tersebut dapat membantu mengidentifikasi, mengevaluasi dan memilih strategi dalam PT XYZ. Dalam penelitian ini membandingkan produk dari PT. XYZ yaitu Sales1CRM dengan competitor dalam industri SAAS yang memberikan layanan CRM. Kompetitor yang dipilih oleh penulis antara lain: HashMicro CRM, EspoCRM, dan Barantum CRM sebagai salah satu penyedia layanan CRM berbasis SAAS di Indonesia. Berdasarkan hasil penelitian yang telah dilakukan dengan menggunakan tiga tahap yaitu, pada tahap pertama PT XYZ mampu memanfaatkan peluang yang ada dan meminimalkan ancaman eksternalnya, PT XYZ memiliki kekuatan yang lebih besar dibandingkan dengan factor kelemahannya, tetapi PT. XYZ masih berada dibawah HashMicro karena jumlah layanan yang disediakan masih terbatas. Sedangkan pada tahap kedua, Matriks SWOT memberikan rekomendasi strategi SO dan dalam matriks SPACE memberikan rekomendasi melakukan strategi agresif untuk tetap memperbesar pangsa pasarnya, serta Matriks Internal-Eksterna merekomendasikan grow and build strategy. Pada tahap ketiga, QSPM memberikan tiga alternatif rekomendasi yaitu, strategi pengembangan produk supaya dapat terus berkembang mengikuti perkembangan teknologi dan alternatif kedua adalah strategi penetrasi pasar serta horizontal integration.
\end{abstract}


Keyword : SWOT Matriks, IFE Matriks, EFE Matriks, Matriks Profil Kompetitif, SPACE Matriks, Matriks Internal Eksternal, QSPM.

\section{PENDAHULUAN}

Persaingan dunia bisnis sekarang ini semakin ketat, diikuti dengan perkembangan teknologi, sistem informasi dan pengetahuan yang dimanfaatkan oleh para pelaku bisnis untuk mengembangkan bisnisnya. PT. XYZ memanfaatkan para pesaing bisnis sekarang ini dengan menyediakan layanan customer relationship management berbasis cloud based. Permasalahan dalam dunia bisnis tidak hanya cukup dengan menjual produk/jasa yang berkualitas, pengiriman barang yang cepat dan harga yang bersaing, tapi lebih kepada pelayanan pelanggan. Pelayanan pelanggan harus dilakukan dengan baik, karena pelanggan tidak akan tertarik untuk membeli barang jika mendapat pelayanan yang buruk dan tidak memuaskan. Terciptanya loyalitas pelanggan disebabkan pelanggan merasa puas atas pelayanan yang diberikan dengan baik. Pelanggan merasa puas jika segala kebutuhan selalu dilayani dengan baik, dengan kepuasan pelanggan akan memberikan pengaruh kepada produk yang ditawarkan atau yang sedang digunakan. Dengan adanya relationship management, perusahaan dapat melakukan analisis data customer dan perusahaan dapat melakukan inovasi terhadap pelayanan konsumen maupun inovasi terhadap produknya. Target utama dengan penggunaan Customer Relationship Management bukan customer satisfaction maupun customer trust, tetapi lebih kepada customer loyality. Dengan diterapkan strategi Customer Relationship Management diharapkan pelanggan akan menggunakan produk atau jasa lebih dari sekali (repurchase intention) jika mereka tidak puas terhadap produk kita, dengan adanya customer loyality maka dapat disertai dengan customer satisfaction dan customer trust.

\section{TUJUAN PENELITIAN}

Tujuan Penulisan karya ini adalah :

- Untuk menganalisis strategi yang sudah dijalani PT XYZ untuk perbaikan strategi jangka panjang dan melihat peluang yang dapat digunakan untuk berkembang dalam industri SAAS (software as a service).

- Untuk mengetahui kondisi internal dan eksternal perusahaan serta mengetahui kondisi persaingan yang industri SAAS untuk meningkatkan daya saing perusahaan.

\section{TINJAUAN PUSTAKA}

- Strategi

Menurut David (2011) dalam Foris dan Mustamu (2015) menyatakan bahwa strategi adalah sarana bersama dengan tujuan jangka panjang yang hendak dicapai. Strategi bisnis mencakup ekspansi geografis, diversifikasi, akuisisi, pengembangan produk, penetrasi pasar, pengetahuan, divestasi, likuidasi dan joint venture. Strategi adalah rencana pelaksanaan dari suatu perusahaan. Rencana tersebut memberikan kerangka untuk keputusan- keputusan manajerial.

- Model Lima Kekuatan dari Porter

Menurut Kodrat (2009) dalam Foris dan Mustamu (2015) menyatakan bahwa tujuan dari analisis lima kekuatan Porter adalah untuk menentukan keunggulan bersaing dan keunggulan kompetitif perusahaan. Menurut David (2006) dalam Foris dan Mustamu (2015), Model Lima Kekuatan Porter tentang analisis kompetitif adalah pendekatan yang digunakan secara luas untuk mengembangkan strategi di banyak industri. Menurut Porter (1980) dalam Candra (2013) menyatakan bahwa hakikat persaingan suatu industry dapat dilihat sebagai kombinasi atas lima kekuatan yaitu:

$>$ Persaingan Perusahaan Sejenis 
Persaingan perusahaan sejenis merupakan kekuatan terbesar dalam lima kekuatan dari porter, perusahaan dapat berhasil jika memberikan keunggulan kompetitif jika dibandingkan dengan perusahaan pesaing

$>$ Pendatang Baru

Pendatang baru dapat ikut masuk dalam industri yang sama, maka dapat meningkatkan intensitas persaingan antar perusahaan meningkat.

Potensi Pengembangan Produk Substitusi

Potensi pengembangan produk substitusi dalam suatu industri dapat mencipatakan batasan harga yang tinggi dan membuat konsumen beralih ke produk substitusi.

$>$ Daya tawar menawar penjual/pemasok

Kekuatan tawar menawar pemasok mempengaruhi intensitas pesaing dalam suatu industri, khusus nya ketika ada sejumlah besar pemasok, ketika hanya sedikit barang substitusi yang cukup bagus atau ketika biaya untuk mengganti bahan baku sangat mahal.

$>$ Daya tawar menawar pembeli/konsumen

Ketika konsumen membeli dalam jumlah besar, kekuatan tawar menawar mereka menjadi kekuatan utama yang mempengaruhi intensitas persaingan dalam suatu industri

- Matriks SWOT

Menurut Ralph (2007) dalam Farhangi (2012) menyatakan bahwa analisis SWOT pertama kali dirancang dan diperkenalkan pada tahun 1960 oleh institut riset Stanford dan pada awal 1975 umumnya digunakan sebagai kerangka analisis untuk merancang strategi perusahaan, dan walaupun lama telah berlalu dari pendahulunya, aplikasi ini masih diterapkan dalam aplikasi penelitian saat ini. Matriks SWOT menganalisis dengan tepat kekuatan dan kelemahan internal serta ancaman dan peluang eksternal untuk memandu strategi yang diharapkan di masa depan.

- Matriks SPACE

Menurut Zendeh (2012) dalam Tafti (2013) menyatakan bahwa Matriks SPACE dan SWOT dianggap sebagai dua alat yang signifikan dan dapat diterapkan untuk mendefinisikan posisi strategis organisasi. Menurut David (2011) dalam Tafti (2013) berpendapat bahwa Matriks SPACE berfokus pada kekuatan finansial dan keunggulan kompetitif sebagai faktor internal dan stabilitas lingkungan dan kekuatan industri sebagai faktor eksternal.

\section{- Quantitative Strategic Planing Matrix (QSPM)}

Dalam Shojaei (2010) menyatakan bahwa QSPM adalah teknik dan metode yang sangat umum dalam evaluasi opsi strategi dan penentuan daya tarik strategi, daya tarik strategi digunakan dalam tahap pengambilan keputusan. Tetapi dalam Zulkarnain (2018) menyatakan bahwa QSPM adalah teknik yang menunjukan secara objektif, mana yang merupakan strategi alternatif terbaik, berdasarkan faktor eksternal dan internal.

\section{METODOLOGI PENELITIAN}

- Jenis dan periode penulisan

Metode penelitian yang dilakukan dengan menggunakan research descriptive (penelitian yang digunakan untuk menggambarkan suatu kejadian, peristiwa, gejala yang berlangsung saat ini atau masa lampau) atau dapat dikelompokkan dalam reaserch evaluation (penelitian yang digunakan untuk memeriksa perjalanan suatu organisasi atau perusahaan). Periode pengumpulan data dilakukan pada bulan November 2017 sampai dengan Maret 2018. 
- Sumber dan Pengumpulan Data

Berdasarkan sumber data, data yang didapatkan merupakan data primer dan data sekunder. Sedangkan pengumpulan data dilakukan dengan melakukan observasi proses development software di kantor pusat sebagai kelompok perusahaan dari PT. XYZ, serta melakukan wawancara kepada manajer SaleslCRM untuk memperoleh data-data primer yang dibutuhkan untuk mendukung penelitian.

- Metode Analisis

Metode analisis yang akan digunakan untuk mendukung penelitian dengan menggunakan beberapa matriks sebagai alat analisis secara objektif guna menghindari pengaruh emosi, kepribadian dan kecenderungan untuk memberi nilai lebih pada suatu faktor tertentu. Teknik-teknik perumusan strategi yang penting dapat diintegrasikan ke dalam kerangka pengambilan keputusan terdiri dari tiga tahap, yaitu Tahap Masukkan (Input Stage), Tahap Pencocokan (Matching Stage), dan Tahap Keputusan.

$>$ Tahap Masukkan (Input Stage)

Pada tahap masukkan dalam kerangka perumusan strategi ini terdiri dari Matriks Evaluasi Faktor Eksternal (External Factor Evaluation Matrix - EFE Matrix), Matriks Evaluasi Faktor Internal (Internal Factor Evaluation Matrix IFE Matrix), dan Matriks Profil Kompetitif (Competitive Profile Matrix - CPM).

$>$ Tahap Pencocokan (Matching Stage)

Tahap pencocokan dari kerangka perumusan strategi terdiri dari tiga teknik yang digunakan yaitu, Matriks SWOT (Strenghts-Weakness-OpportunitiesThreats Matrix), Matriks SPACE (Strategic Position and Action Evaluation Matrix) dan Matriks Internal-Eksternal.

Tahap Keputusan

Pada tahap keputusan ini menggunakan QSPM, QSPM adalah teknik analisis dalam literatur yang dirancang untuk menentukan daya tarik relatif. Daya tarik strategi digunakan dalam tahap pengambilan keputusan.

\section{HASIL DAN KESIMPULAN}

Berdasarkan penelitian yang telah dilakukan oleh penulis, terdapat beberapa metode yang dilakukan untuk mendukung penelitian ini:

- Analisis dasar dengan metode Lima Kekuatan Porter

$>$ Persaingan dalam Industri SAAS dengan melakukan komparasi dengan HashMicro CRM, EspoCRM, Barantum CRM sebagai salah satu penyedia layanan CRM berbasis SAAS di Indonesia.

$>$ Konsumen menuju pada perusahaan-perusahaan yang belum menggunakan sistem untuk membantu menjalankan setiap pekerjaan karyawannya.

> Pendatang baru dalam industri ini akan lebih susah karena industri harus mengikuti perkembangan teknologi yang pesat serta menyiapkan modal awal yang besar untuk menyediakan server yang digunakan sebagai data center.

$>$ Produk Substitusi yang muncul akan sulit untuk memasuki perusahaan yang telah memanfaatkan produk Sales1CRM karena saat data-data penting sudah tersimpan dalam data center dan merasa aman maka customer akan merasa loyal.

- Analisis dengan Matriks Evaluasi Faktor Eksternal (EFE) menghasilkan skor bobot 2.72 yang mencerminkan bahwa PT. XYZ secara efektif cukup mampu menarik keuntungan dari peluang yang ada dan meminimalkan pengaruh negatif potensial dari ancaman eksternalnya. Hal ini dapat dinilai dari total skor bobot peluang 2.11 sedangkan total skor bobot pada faktor ancaman 0.61. 
- Analisis dengan Matriks Evaluasi Internal (IFE) perolehan diatas rata-rata yaitu 3.02, ini menunjukan bahwa PT. XYZ memiliki posisi kekuatan internal dalam menghadapi persaingan pasar industri SAAS lebih besar dari faktor kelemahannya.

- Analisis dengan Matriks Profil Kompetitif dibandingkan dengan kompetitornya, bahwa Sales1CRM masih berada dibawah Hashmicro tetapi masih lebih unggul jika dibandingkan dengan EspoCRM. SaleslCRM memperoleh total skor 3.14, kemudian Hashmicro 3.68 dan EspoCRM 3.02.

- Analisis dengan Matriks SWOT memberikan kesimpulan dengan mempertimbangkan faktor internal dan eksternal PT. XYZ adalah diprioritaskan pada strategi SO dengan memanfaatkan kekuatan internal perusahaan dan menarik keuntungan dari peluang eksternalnya. Fokus pada strategi SO karena kekuatan perusahaan menjadi halangan bagi kompetitor untuk menyerang, sedangkan peluang bagi perusahaan akan menjadikan kesempatan perusahaan untuk berkembang. dengan berfokus pada dua faktor tersebut diharapkan perusahaan menjadi semakin kuat menghadapi persaingan dan perusahaan semakin berkembang menjadi yang terbaik.

- Analisis dengan Matriks SPACE menghasilkan nilai rata-rata untuk dimensi Environmental Stability (ES) adalah $-9.0 \div 4=-2.25$, sedangkan rata-rata untuk dimensi Competitive Advantage (CA) adalah $-6.0 \div 4=-1.50$. Rata-rata untuk Industry Strength (IS) adalah $18.0 \div 4=4.50$, sedangkan rata-rata untuk Financial Strength (FS) adalah $17.0 \div 4=4.25$. Dari faktor-faktor pembentuk matriks SPACE dihasilkan koordinat vektor sumbu $\mathrm{x}=3.00$ dan sumbu $\mathrm{y}=2.00$ sehingga bila digambarkan dalam matriks, absis dan ordinatnya akan berada pada kuadran agresif. Berdasarkan rekomendasi strategi agresif, perusahaan dapat melakukan integrasi kedepan atau kebelakang, penetrasi pasar, pengembangan pasar, pengembangan produk.

- Analisis Matriks Internal-Eksternal menunjukan perusahaan berada pada kuadran IV yaitu grow and build strategy serta direkomendasikan melakukan integrative (backward, forward and horizontal integration) dan intensive (market penetration, market development, and product development). Strategi market penetration dilakukan dengan memberikan harga yang murah dengan kualitas yang baik sesuai dengan kebutuhan klien dengan dikombinasi dengan iklan-iklan pada media sosial.

- Analisis QSPM menghasilkan strategi pengembangan produk memiliki skor daya tarik yang paling tinggi sedangkan rekomendasi kedua adalah strategi penetrasi pasar adalah strategi mempertahankan atau meningkatkan pangsa pasar produk, dengan di dukung harga yang kompetitif, iklan, promosi. Serta rekomendasi terakhir adalah Horizontal Integration adalah meningkatkan kepemilikan atau kontrol pada perusahaan sejenis, dapat dilakukan dengan merger. Berdasarkan hasil analisis pada QSPM memperoleh hasil untuk pengembangan produk dengan nilai 7.19, untuk penetrasi pasar mendapat nilai 6.69 sedangkan untuk horizontal integration mendapat nilai 5.49

Berdasarkan hasil penelitian ini akan disimpulkan:

- Hasil analisa pada tahap pertama:

$>$ PT. XYZ mampu memanfaatkan peluang yang ada dan meminimalkan ancaman eksternalnya.

$>$ PT. XYZ memiliki kekuatan yang lebih besar dibandingkan dengan faktor kelemahannya

PT. XYZ masih berada dibawah Hashmicro karena jumlah layanan yang masih terbatas 
- Berdasarkan hasil analisis pada tahap pencocokan dapat diperoleh kesimpulan bahwa pada Matriks SWOT memberikan rekomendasi strategi SO dan dalam matriks SPACE memberikan rekomendasi melakukan strategi agresif untuk tetap memperbesar pangsa pasarnya. Sedangkan Matriks Internal-Eksternal merekomendasikan grow and build strategy.

- Berdasarkan hasil analisis pada tahap keputusan dengan QSPM diperoleh rekomendasi strategi pengembangan produk supaya dapat terus berkembang mengikuti perkembangan teknologi. Alternatif kedua adalah strategi penetrasi pasar, dan yang ketiga adalah Horizontal Integration.

\section{DAFTAR PUSTAKA}

Kodrat., (2009). Konsep Lima Kekuatan Porter. Jakarta : PT. Binarupa Aksara.

David, F. R., (2006). Strategic Management. New Jersey. Prentice Hall.

David, F. R., (2011). Strategic Management: Concepts and Cases (13th ed.).

David, F. R., (2009). Manajemen Strategis Konsep.

Ralph, F. S., (2007). Business process management and the balanced scorecard:using processes as strategic drivers: John Wiley \& Sons, Inc.

Farhangi, A. K., et al. (2012). Development SWOT Matrix for Strategic Planning in Media Organizations: International Journal of Business and Commerce.

Foris, P. J., dan Mustamu, R. H., (2015). Analisis Strategi pada perusahaan Plastik dengan Porter Five Forces: AGORA.

Candra, S., (2013). Aplikasi Model Lima Kekuatan Porter pada Restoran Drupadi: Binus Business Review.

Porter, M. E., (1980). Competitive Strategy: Techniques for Analyzing Industries and Competitors $\left(1^{\text {st }}\right.$ ed.). New York, YN: Free Press.

Tafti, S. F., et al. (2013). Assessment and Analysis Strategies According to SPACE Matrix-case study: Petrochemical and Banking industries in Tehran Stock Exchange (TSE): Social and Behavioral Sciences.

Zandeh, B., et al. (2012). A new Approach to SPACE Matrix: International Conference on Economics and Finance Research IPEDR Vol.32. IACSIT Press, Singapore.

Meredith, E. D., and Forest, R. D., (2009). The Quantitative Strategic Planning Matrix (QSPM) applied to a Retail Computer Store: The Coastal Business Journal.

Shojaei, M. R., et al. (2010). Strategic Planning for a Food Industry Equipment Manufacturing Factor, using SWOT Analysis, QSPM, and MAUT models: Asian Journal of Management Research.

Zulkarnain, A., et al. (2018). Analysis of IFE, EFE and QSPM matrix on Business Development Strategy. IOP Conference Series: Earth and Environmental Science. 
